Florida International University FIU Digital Commons

FCE LTER Journal Articles

FCE LTER

4-5-2017

\title{
Scale and spatial consistency of specialization in an endemic and abundant freshwater diatom from the Caribbean Basin
}

\author{
Viviana Mazzei \\ Department of Biological Sciences and Southeast Environmental Research Center, Florida International University, \\ vmazz001@fiu.edu \\ Evelyn E. Gaiser \\ Department of Biological Sciences and Southeast Environmental Research Center, Florida International University, \\ gaisere@fiu.edu
}

Follow this and additional works at: https://digitalcommons.fiu.edu/fce_lter_journal_articles

Part of the Life Sciences Commons

\section{Recommended Citation}

Viviana Mazzei and Evelyn Gaiser, "Scale and spatial consistency of specialization in an endemic and abundant freshwater diatom from the Caribbean Basin," Freshwater Science 36, no. 3 (September 2017): 542-554.

This material is based upon work supported by the National Science Foundation through the Florida Coastal Everglades Long-Term Ecological Research program under Cooperative Agreements \#DBI-0620409 and \#DEB-9910514. Any opinions, findings, conclusions, or recommendations expressed in the material are those of the author(s) and do not necessarily reflect the views of the National Science Foundation. This work is brought to you for free and open access by the FCE LTER at FIU Digital Commons. It has been accepted for inclusion in FCE LTER Journal Articles by an authorized administrator of FIU Digital Commons. For more information, please contact dcc@fiu.edu, jkrefft@fiu.edu. 


\title{
Scale and spatial consistency of specialization in an endemic and abundant freshwater diatom from the Caribbean Basin
}

\author{
Viviana Mazzei ${ }^{1,2}$ and Evelyn Gaiser ${ }^{1,3}$ \\ ${ }^{1}$ Department of Biological Sciences and Southeast Environmental Research Center, Florida International University, Miami, \\ Florida 33199 USA
}

\begin{abstract}
We used populations of an abundant diatom in calcareous microbial mats, Encyonema evergladianum, from 3 karstic wetlands in the Caribbean Basin to test whether the relative abundance of this species is more strongly driven by macrohabitat features (landscape-scale gradients of conductivity and P availability) or mat microhabitat characteristics (biomass and mineral content), and whether specialization is maintained in populations from geographically separated but environmentally similar wetlands. We found that, across Caribbean wetlands, the abundance of E. evergladianum was most strongly tied to microbial-mat biomass, suggesting that this species is specialized for, and probably contributes to, the unique conditions of these mats. However, the magnitude and importance of micro- and macroscale drivers on E. evergladianum abundance differed among wetlands, which implies that this diatom has differentiated ecotypically across its range. We found no morphological correlates to potential ecotypes, making it difficult to distinguish between ecotypes without molecular studies. We also searched for an engineering role of E. evergladianum in mat structure by examining freeze-fractured mat fragments under scanning electron microscopy, but found no morphological evidence for functional contributions to mat cohesion. Encyonema evergladianum is a consistently strong indicator of oligotrophic, freshwater conditions that promote calcareous microbial mats in coastal karstic wetlands of the Caribbean. Variability in the scales of specialization by microbial species requires calibration of quantitative, abundance-based approaches to habitat assessment in the context of individual wetlands, particularly in these wetlands where ecosystem-scale changes are abrupt in response to climate and anthropogenic changes in nutrient delivery and salinity.
\end{abstract}

Key words: ecological specialization, ecotypes, Encyonema evergladianum, diatom indicators, karstic wetlands, Caribbean Basin

The distribution and abundance of species are controlled by environmental, spatial, and historical factors, the relative importance of which varies according to the shape of environmental gradients, taxon life-history strategies, and the spatiotemporal scales of metapopulation dynamics (Chase and Myers 2011, Weiher et al. 2011). For habitat specialists, abundance patterns are thought to be under stronger control by environmental rather than dispersal-related or historical processes because their narrow environmental tolerances restrict them to certain habitat features or conditions (Kolasa and Romanuk 2005, Pandit et al. 2009, Devictor et al. 2010). Relative abundance provides a measure of species performance and can be used to define specialization when abundance is greatest within a narrow range of environmental and biological conditions (Futuyma and Moreno 1988). Specialization also can be defined by the species' role in or effect on its environment (i.e., functional specialization), as with ecosystem engineers (Devictor et al. 2010). The confinement of specialist species to certain environmental conditions or habitats makes them potentially powerful indicators of changes in environmental conditions and habitat availability, including those caused by anthropogenic pressures, such as climate change and eutrophication (Soininen 2007). However, a clear understanding of the drivers of specialization and the scale at which they operate is critical to using specialists as indicators of environmental change. Fur-

E-mail addresses: ${ }^{2}$ vmazz001@fiu.edu; ${ }^{3}$ gaisere@fiu.edu

DOI: 10.1086/693105. Received 7 November 2016; Accepted 5 April 2017; Published online 22 June 2017.

Freshwater Science. 2017. 36(3):542-554. ๑ 2017 by The Society for Freshwater Science. 
thermore, extrapolation of indicators developed in one location to other similar environments is often desirable but requires knowledge about the maintenance of specialization across space.

Key environmental factors influencing the abundance and distribution of species can occur at different scales and may have cascading effects on one another making it difficult to determine which factors exert the strongest control on species performance and, thus, define its specialization. For example, in the Florida Everglades and similar karstic wetlands throughout the Caribbean Basin, P availability and conductivity are landscape scale (macroenvironmental) drivers of the quantity (i.e., biomass), quality (i.e., mineral content), and species composition of the characteristic calcareous microbial mats found throughout these systems. However, these 2 macroenvironmental drivers interact with characteristics of the mat itself (microhabitat drivers) that regulate and are regulated by mat-dwelling organisms and their interactions. The integrity of calcareous mats and their unique species composition depend on preservation of the natural environmental conditions found in karstic wetlands, particularly low conductivity and P (Rejmánková and Komárková 2005, Gaiser et al. 2006, 2011, Slate and Stevenson 2007, Hagerthey et al. 2011). These landscapes are naturally P-limited systems with low conductivity that exhibit a gradient of increasing $\mathrm{P}$ and conductivity from interior freshwater marshes to the coast. However, saltwater intrusion coupled with water-management practices are altering this natural gradient with important consequences for the ecological communities found there (Childers et al. 2006, Price et al. 2006, La Hée 2010, Saha et al. 2011, La Hée and Gaiser 2012). Calcareous microbial mats are especially sensitive to elevated $\mathrm{P}$ concentrations, which trigger biogeochemical processes within the mats that cause them to break down and eventually to be replaced by noncalcitic filamentous mats or biofilms with different algal communities (Gaiser et al. 2006, 2011, Hagerthey et al. 2011). Calcareous microbial mats are usually absent in areas closer to the coast where conductivity is higher, but their absence from these areas has not been directly linked to conductivity and may be a result of the relatively higher $\mathrm{P}$ concentrations that occur there than in interior marshes (Childers et al. 2006). Elevated $\mathrm{P}$ and conductivity are associated with decreased abundance of calcareous microbial mats and replacement by noncalcitic mats, but the effect of these macroenvironmental drivers on species composition, particularly of the diatom community, can be confounded by their effect on the structure of the mat microhabitat in which these species live (i.e., microhabitat-scale drivers).

Shifts in microbial mat community composition, particularly the diatom assemblages, have been associated with changes in $\mathrm{P}$ and conductivity, but the degree to which the relative abundance of these diatoms reflects their preferences and tolerances for these macroenvironmental drivers or the cascading effects of these drivers on mat structure and function remains uncertain. $\mathrm{P}$ enrichment can initiate compositional changes associated with mat breakdown including the loss of calcium-carbonate precipitating cyanobacterial species (i.e., Schizothrix and Scytonema) that form the backbone of calcareous mats and diatoms that contribute to mat cohesion (i.e., Mastogloi acalcarea (syn. M. smithii); Gaiser et al. 2006, 2011, Hagerthey et al. 2011). Elevated conductivity also creates unfavorable conditions for calcareous mat formation, as evidenced by their absence from coastal marshes, because changes in ion concentrations alter mat chemistry and trigger bacterial and algal community composition shifts to species that form organic mats and biofilms. However, these effects have not been tested experimentally. Calcareous microbial mats contain several endemic diatom species, some of which play important roles in mat formation and cohesion (Slate and Stevenson 2007, Gaiser et al. 2010). The distribution and abundance patterns of these endemic species suggest specialization for the chemical and biological conditions found in these microhabitats indicating that at least some of these species respond to the loss of calcareous mat habitat, driven by the replacement of ecosystem-engineer species that play a functional role in mat formation rather than by elevated $\mathrm{P}$ and conductivity directly. To understand specialization properly in these diatom communities and in general, we must address whether these apparent niche restrictions are caused directly by tolerances for factors acting at the macroenvironmental scale or indirectly through the effects of those drivers on the immediate microhabitat experienced by these microorganisms.

The consistency of the drivers across geographically separated but environmentally similar habitats also must be addressed to extend species-based metrics of environmental change developed in one location to other ecologically similar ecosystems. Extrapolation of habitat preferences of a specialist in one location to other suitable habitats depends on how and whether preferences are preserved across the regional population. Their environmental specificity implies that specialist species respond to environmental gradients consistently across their geographic range, but the environmental or biological circumstances under which specialization originated may have differed in some areas of the species' range causing the population to diverge into subpopulations with differing levels of specialization (Futuyma and Moreno 1988, van Tienderen 1991, Bolnick et al. 2003). This process, called ecotypic differentiation, occurs through the evolution of genotypes or when existing genetic variability within a population is differentially expressed as environments change over time and can result in nonconformity of ecological preferences or morphologies among subpopulations (Sultan and Spencer 2002, Poisot et al. 2011). Nonconformity could be a problem if species-based ecological predictions developed for one ecosystem are applied elsewhere because subpopulations from different locations cannot be expected to respond in the same ways to changing 
environmental conditions. For example, diatom communities are used commonly as ecological indicators of nutrient enrichment and elevated conductivity in the Everglades where natural water quality is being altered by saltwater intrusion caused by sea-level rise and water-management practices (Frankovich et al. 2006, Wachnicka et al. 2010, La Hée and Gaiser 2012, Bramburger et al. 2013, Lee et al. 2013). However, similar metrics have not been well established in other karstic wetlands in the Caribbean Basin. Understanding whether diatom indicators respond to the same drivers across karstic wetlands in the Caribbean Basin or if specialization is context dependent would allow us to extend Everglades-based metrics to encompass the entire region. Such knowledge also would contribute to an understanding of ecotypic differentiation in microorganisms that are easily dispersed, such as diatoms. Because the regional diatom species pool of the Caribbean Basin probably is not limited by dispersal given the relatively short distances among karstic wetlands in the region $(<1500 \mathrm{~km}$; Potapova and Charles 2002, van der Gucht et al. 2007, Bennett et al. 2010), differences in specialization among populations from individual wetlands can be assumed to reflect environmental differences rather than dispersal barriers. Furthermore, the possibility for ecotypic differentiation without morphological correlates must be appreciated in studies of ecological indicator species that are based solely on morphological traits, such as diatoms whose identification is based largely on frustular ornamentation.

We used populations of an abundant and endemic matdwelling diatom, Encyonema evergladianum, from subtropical and tropical karstic wetlands to test 3 hypotheses. 1) Microhabitat-scale features (i.e., mat ash-free dry mass [AFDM] and mat mineral content) are stronger determinants of the relative abundance of mat-dwelling diatom species than macroenvironmental drivers (i.e., landscape conductivity and $\mathrm{P}$ gradients). We propose that specialization at the micro scale is a result of the integration of macroscale environmental (abiotic) gradients with microhabitat conditions mediated by biological interactions. 2) Microhabitat specialization has been maintained across karstic wetland landscapes in the Caribbean Basin because the presumed environmental similarity and capacity for dispersal among karstic wetlands should prevent divergent selection into separate ecotypes. If this hypothesis is false, we expect that long-term ecological differences among karstic wetlands in the Caribbean Basin have caused populations to diverge into distinct ecotypes that can be differentiated based on morphology. We tested this hypothesis by comparing morphometric data of E. evergladianum from each wetland to assess whether populations exhibit distinct morphologies based on location. 3) Mat-dwelling diatoms whose abundance is most strongly related to microhabitat quantity and quality can be expected to play a role in the creation and maintenance of the mat microhabitat structure given that dominant species often influence their surroundings. We investigated the engineering role of $E$. evergladianum in calcareous microbial mats by examining scanning electron micrographs of freeze-fractured mat fragments, which capture the ultra-ecology and morphology of this diatom.

\section{METHODS}

Encyonema evergladianum was first described by Krammer (1997) from samples collected in the Florida Everglades (but see Mazzei 2014). It has been described as endemic to tropical and subtropical karstic wetlands with a particularly high affinity for the calcareous microbial-mat microhabitats found in these ecosystems (Slate and Stevenson 2007, La Hée and Gaiser 2012). It is reduced in abundance when calcareous mats disappear in the presence of high conductivity and $\mathrm{P}$ and, therefore, has been identified as a valuable indicator of oligotrophic, freshwater conditions (Slate and Stevenson 2007, Gaiser et al. 2006, Wachnicka et al. 2010). These characteristics make it an ideal organism with which to address the ecological questions we pose. The results of our research will help establish the strength of this species as a regional bioindicator for freshwater karstic wetlands in the Caribbean Basin that are threatened in similar ways by saltwater intrusion, freshwater diversion, and nutrient enrichment (Gaiser et al. 2015).

\section{Scale and maintenance of drivers of specialization across wetlands}

We investigated specialization for drivers operating at different scales by examining the response of E. evergladianum relative abundance to 2 macroenvironmental drivers, conductivity and mat total P (TP) concentration, and 2 micro-scale drivers, mat AFDM and mineral content, in 3 karstic wetlands of the Caribbean Basin: the Everglades (Florida, USA), Sian Ka'an Biosphere Reserve (Yucatan, Mexico), and the New River Lagoon (Belize). We used mat TP to estimate TP in the environment and, therefore, we consider mat TP a macroenvironmental driver in our paper. Mat TP can be a more sensitive gauge of $\mathrm{P}$ loading than concentrations in the water column because $\mathrm{P}$ inputs are taken up rapidly by microbial mats and other vegetation, and it is virtually undetectable in the water column (Gaiser et al. 2004). Mat areal AFDM represents the amount of organic biomass per unit area available for occupation by diatoms and other organisms, and we used it as a measure of habitat availability. We used \% mat mineral (i.e., inorganic) content as a proxy for mat calcareousness because mats with higher mineral content also have high calcium carbonate concentrations. Samples were collected during the wettest time of year along freshwater-to-coastal gradients of increasing P availability and conductivity from 12 sites in the Everglades (2013), Yucatan (2006), and Belize (2007) for a total of 36 sites (see summary in La Hée and Gaiser 2012). 
At each site, we measured conductivity $(\mu \mathrm{S} / \mathrm{cm})$ with a YSI 30 Pro meter (Yellow Springs Inc., Yellow Springs, Ohio) and harvested microbial mats from a $1-\mathrm{m}^{2}$ quadrat. We placed the harvested material in a perforated graduated cylinder to drain excess water and measured total mat biovolume $\left(\mathrm{mL} / \mathrm{m}^{2}\right)$. We placed a $120-\mathrm{mL}$ subsample of the total harvested material in a plastic sample bag, transported it back to the laboratory on ice, and stored it in a $-20^{\circ} \mathrm{C}$ freezer until processed. We thawed samples and transferred them to clean Tupperware dishes where plant material, rocks, or other fragments were removed using forceps. We homogenized the cleaned periphyton in a $500-\mathrm{mL}$ beaker with a hand-held blender. The volume of the homogenized sample was recorded to account for dilution with deionized (DI) water used to facilitate cleaning and homogenizing the sample. We placed the beaker on a stir plate and subsampled for TP content, biomass, and E. evergladianum relative abundance.

We placed the biomass subsample in a drying oven at $80^{\circ} \mathrm{C}$ for $\geq 48 \mathrm{~h}$ to obtain a dry mass (DM; g) measurement and then in a furnace where it was combusted at $500^{\circ} \mathrm{C}$ for $1 \mathrm{~h}$ to obtain an ash (mineral) mass (g). We calculated AFDM, organic biomass, by the loss-on-ignition method as the difference between the ash mass and the total DM and standardized to area $\left(\mathrm{g} / \mathrm{m}^{2}\right)$ by scaling the subsample biomass to the total area sampled and correcting for dilution with deionized (DI) water during the cleaning process. We calculated mat mineral content as the \% ash mass of the total DM. We dried the TP subsamples at $80^{\circ} \mathrm{C}$ and pulverized them with a mortar and pestle. We processed a known amount of each subsample based on colorimetric analysis to estimate TP concentration, expressed as $\mu \mathrm{g} / \mathrm{g}$ mat DM, following the methods of Solorzano and Sharp (1980).

We cleaned the diatom subsamples of mineral debris and organic matter with the sulfuric acid oxidation methods published by Hasle and Fryxell (1970). We pipetted a known volume of cleaned diatom samples onto glass coverslips, permanently mounted them on microscope slides with Naphrax (PhycoTech, St. Joseph, Michigan) mounting medium, and viewed them under a compound light microscope. We identified $E$. evergladianum valves among $\geq 500$ diatom valves counted along random transects at $600 \times$ magnification under oil immersion.

We organized the data into 4 groups for statistical analysis: Everglades, Belize, Yucatan, and the 3 locations combined, and used 1-way analysis of variance (ANOVA) test for differences in E. evergladianum abundance, TP, conductivity, periphyton AFDM, and mineral content among the 3 locations. When significant differences were present, we used Tukey's post hoc test to identify which locations differed. We created Pearson correlation matrices for the Everglades, Belize, and Yucatan data sets to explore the independent relationships among all 4 variables in each wetland. We then used multiple linear regressions for each of the 4 data sets to assess which variable(s) best explained E. evergladianum abundance at the local scale of individual wetlands and at the regional scale of the Caribbean Basin (combined data set). Conductivity, TP, and AFDM were $\log (x)$-transformed to improve linearity and 2 extreme conductivity outliers were removed from the Yucatan data set. Statistical analyses were performed in R (version 3.1.2; R Project for Statistical Computing, Vienna, Austria) and SPSS (version 23; IBM, Armonk, New York).

\section{Morphological ecotypes}

We compared morphometric data from each of the 3 locations to assess whether populations of E. evergladianum from different locations express distinct morphologies that reflect possible ecological difference among them. We measured taxonomically diagnostic morphological features, including length $(\mathrm{L})$, width $(\mathrm{W}), \mathrm{L}$ : W ratio, striae density, and dorsal valve curvature, for 35 individuals from each location, and we attempted to capture the widest range of valve sizes. We calculated curvature with the methods given by Bixby and Zeek (2010). All morphometric measurements were made from digital images taken through a light microscope (Axioskop 2; Zeiss, Thornwood, New York) equipped with differential interference contrast and a digital camera (DFC425; Leica, Wetzlar, Germany). Digital images were analyzed and prepared for publication using GIMP 2.8.10 (The GIMP team; www.gimp.org). Nonmetric multidimensional scaling (NMDS) and analysis of similarity (ANOSIM) were performed using PRIMER 6 (PRIMER-E, Albany, Auckland, New Zealand) to assess whether individuals of E. evergladianum form significantly different groups corresponding to the Everglades, Belize, and Yucatan locations based on frustular morphology. Vectors were fitted onto the ordination to visualize which morphological features are driving any observed clustering.

\section{Functional specialization within the microhabitat}

We investigated potential functional specialization in E. evergladianum by examining scanning electron micrographs of freeze-fractured mat fragments to search for physical evidence that this diatom contributes to microhabitat formation; e.g., mucilage secreting pores, mucilaginous sheaths, stalks, or other structures that might contribute to mat cohesion. We fixed calcareous microbial mats collected from the 12 Everglades sites in $2 \%$ glutaraldehyde and stored them in $20-\mathrm{mL}$ scintillation vials until processed. Mat samples from the Belize and Yucatan site were unavailable for scanning electron microscope (SEM) analysis. We prepared the mats for the SEM by first decanting the glutaraldehyde and washing the samples with DI water before freezing the samples in liquid $\mathrm{N}$ and fracturing them with a hammer and chisel. We transferred the fragments back to the scintillation vials 
where they were dehydrated in a series of increasing concentrations $(40,60,80$, and $100 \%)$ of ethyl alcohol. We further dehydrated the samples by critical-point drying in a Tousimis samdri-PVT-3D critical point dryer (Tousimis ${ }^{\circledR}$, Rockville, Maryland) to preserve the 3-dimensional structure of the mats. We mounted the dehydrated samples on stubs and coated them with $\mathrm{Au}$ for observation with the SEM (JEOL JSM 5900LV; Florida Center for Analytical Electron Microscopy, Florida International University, Miami, Florida). In addition, we observed live specimens of E. evergladianum from wet mounts of diatom samples from each of the 3 wetlands to search for evidence of functional specialization that may have been destroyed during the preparation of samples for SEM analysis. For example, nonmotile species of Encyonema often grow in colonies within mucilaginous tubes that potentially contribute to mat structure and cohesion. However, the growth form of E. evergladianum is not known and is important in understanding the role of this species in microbial mat engineering.

\section{RESULTS}

\section{Scale and maintenance of drivers of specialization across wetlands}

Mean E. evergladianum abundance did not differ among the 3 karstic wetlands (Fig. 1A). Conductivity was significantly higher in the Yucatan than the other 2 wetlands, but all 3 locations had similar values of mat TP (Fig. 1B, C). Periphyton from the Everglades did not have significantly higher mineral content than either other location, but AFDM was significantly greater in the Everglades than in the Yucatan and Belize (Fig. 1D, E).

Pearson correlations revealed that the Everglades, Belize, and Yucatan wetlands have different environments with unique interactions among drivers (Table 1). Mat mineral content was negatively correlated with mat TP at all 3 locations and with conductivity only in the Everglades. Conductivity and mat TP were positively correlated in the Everglades and negatively correlated in the Yucatan. The correlations among E. evergladianum abundance and environmental drivers were not consistent across the 3 locations (Table 1). Encyonema evergladianum abundance was negatively correlated with mat TP and positively correlated with mat mineral content (mat calcareousness) and AFDM in the Everglades and Belize but not in the Yucatan. Encyonema evergladianum abundance and conductivity were negatively correlated in the Everglades and the Yucatan.

The multiple linear regression analyses indicated that E. evergladianum abundance responded more strongly to microhabitat availability (periphyton AFDM) than to macroenvironmental factors at the regional scale, but this response was not always consistent at the local scale of individual wetlands (Table 2). AFDM was the strongest driver of abundance in Belize and the Everglades, but not in the Yucatan where conductivity, followed by TP, had the strongest influence on relative abundance (Fig. 2A-D, Table 2).

\section{Morphological ecotypes}

The ANOSIM and post hoc test on E. evergladianum frustular morphology provided evidence for the existence of morphological ecotypes among the 3 populations. The ANOSIM was significant $\left(R^{2}=0.174, p=0.001\right)$ and pairwise comparisons showed that specimens from the Everglades, Belize, and Yucatan were all significantly different from one another $(p<0.05)$. However, based on the regression analyses, we expected only the Yucatan population to express significantly different morphology from the other 2 wetlands. The unexpected significant morphological differences between the Everglades and Belize populations do not appear to have an ecological basis given that the regression analysis did not reveal ecotypic differentiation in these populations. The NMDS plot shows considerable overlap among wetlands, the separation of Everglades specimens from Belize and Yucatan specimens is clear and is supported by the results of the ANOSIM, which established that the Everglades population is more dissimilar from the Belize and Yucatan populations than these 2 are from each other based on the morphological vectors fitted onto the ordination (Fig. 3). Specimens from the Everglades have longer and wider valves than those from Belize and Yucatan (Fig. 4AC, Table 3).

\section{Functional specialization within the microhabitat}

Encyonema evergladianum in calcareous microbial mats (Fig. 5A) was embedded in the extracellular polymeric substance (EPS) matrix that cements the mats into cohesive assemblages (Fig. 5B). Contrary to our expectation, we did not observe attachment structures or structures producing extracellular mucilage that could contribute to mat cohesion, or any evidence of calcium carbonate formation along its margins (Fig. 5C, D). Wet mounts of the diatom samples provided observations of live E. evergladianum specimens when viewed under the light microscope. In these wet mounts, we did not observe colonies of E. evergladianum growing in tubes. Instead, this species was highly motile, which may explain the lack of attachment structures.

\section{DISCUSSION}

Our results suggest that the relative abundance of the regional E. evergladianum population is most strongly driven by microscale features of the local habitat, particularly calcareous microbial-mat biomass, an important ecosystem component of karstic, freshwater wetlands. However, subpopulations from the 3 wetlands, particularly the Yucatan, did not respond consistently to the environmental drivers considered in our study. This result suggests that divergent selection may have led to the evolution of ecotypes within 

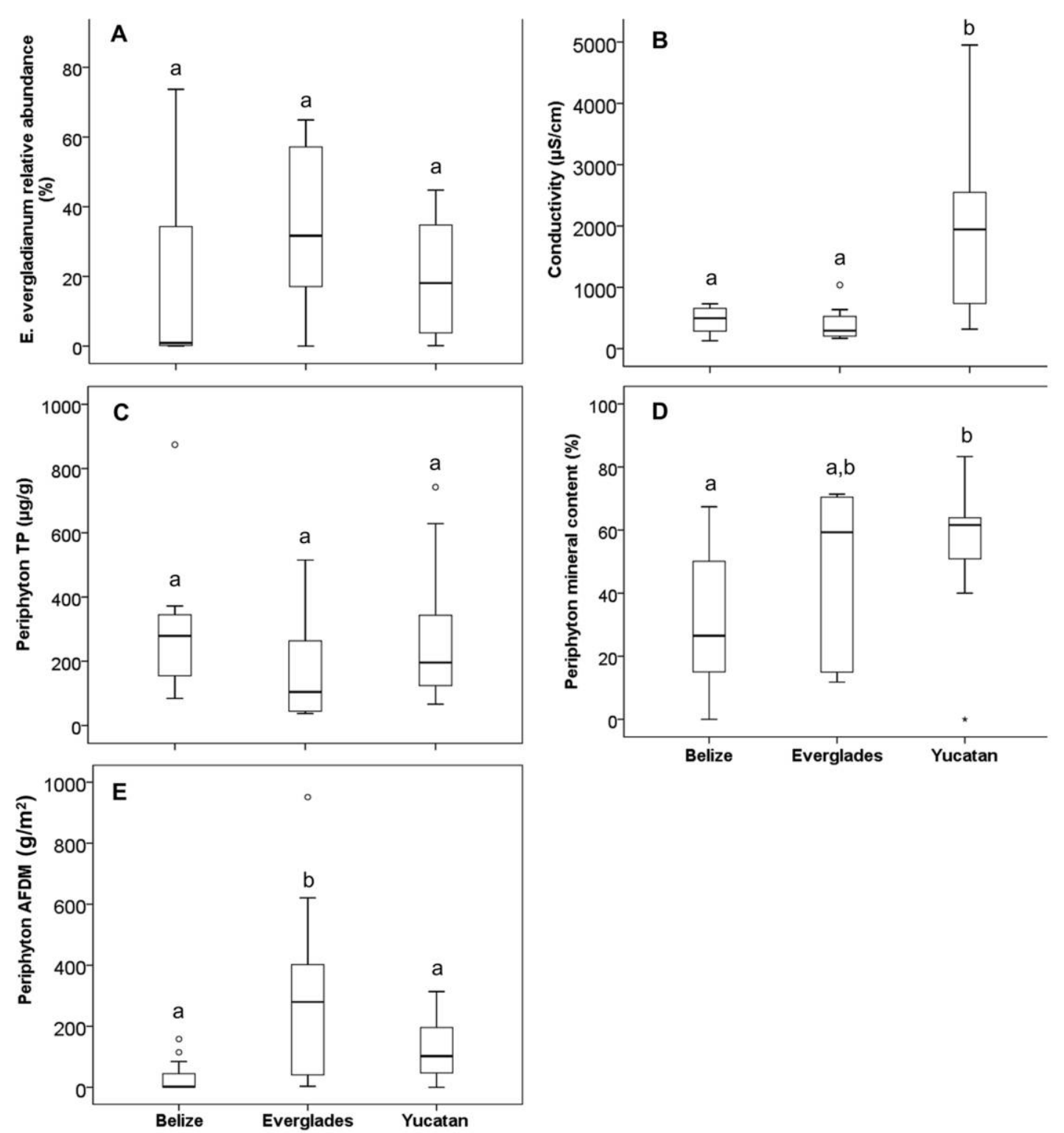

Figure 1. Box-and-whisker plots for Encyonema evergladianum abundance (A), conductivity (B), periphyton total P (TP) (C), periphyton mineral content (D), and periphyton ash-free dry mass (AFDM) (E) for Belize, Everglades, and Yucatan. Lines in boxes are medians, box ends are quartiles, whiskers are max and min values, circles are outliers, and asterisks are extreme outliers. Boxes with the same lowercase letter are not significantly different $(p \geq 0.05)$.

the Caribbean Basin. Morphological differences among the 3 subpopulations did not reflect the ecological difference observed in the Yucatan subpopulation. Furthermore, we did not observe any structures that would confer an engineering role in calcareous periphyton mat construction or maintenance in E. evergladianum and, therefore, we found no evidence of functional specialization. The occurrence of ecotypic differentiation in diatom species, despite their lack of significant dispersal barriers on intermediate spatial scales and the absence of morphological correlates to help identify ecotypes has important implications for the use of diatoms in ecosystem assessments to infer or predict environmental conditions on both regional and local scales.

Encyonema evergladianum is considered an indicator species of low P and conductivity in the Everglades (Gaiser et al. 2006, Wachnicka et al. 2010, Frankovich and Wachnicka 2015) and other karstic wetlands of the Caribbean (La Hée and Gaiser 2012). However, we hypothesized that the decline in E. evergladianum abundance along gradients of increasing $\mathrm{P}$ and conductivity results from the replacement of calcareous microbial mats by noncalcareous mats at the high end of these gradients, rather than to these en- 
Table 1. Correlations between Encyonema evergladianum \% relative abundance, total P (TP), ash-free dry mass (AFDM), \% mineral content, and conductivity for each region given by Pearson correlation coefficients. ${ }^{*}=p<0.05$.

\begin{tabular}{|c|c|c|c|c|c|c|c|c|c|c|c|c|}
\hline \multirow[b]{2}{*}{ Variable } & \multicolumn{4}{|c|}{ Everglades } & \multicolumn{4}{|c|}{ Belize } & \multicolumn{4}{|c|}{ Yucatan } \\
\hline & $\begin{array}{c}\text { Mineral } \\
(\%)\end{array}$ & $\begin{array}{c}\text { Abundance } \\
(\%)\end{array}$ & $\begin{array}{c}\log \\
(\mathrm{TP}) \\
(\mu \mathrm{g} / \mathrm{g})\end{array}$ & $\begin{array}{c}\log \\
(\mathrm{AFDM}) \\
\left(\mathrm{g} / \mathrm{m}^{2}\right)\end{array}$ & $\begin{array}{c}\text { Mineral } \\
(\%)\end{array}$ & $\begin{array}{c}\text { Abundance } \\
(\%)\end{array}$ & $\begin{array}{c}\log \\
(\mathrm{TP}) \\
(\mu \mathrm{g} / \mathrm{g})\end{array}$ & $\begin{array}{c}\log \\
(\text { AFDM }) \\
\left(\mathrm{g} / \mathrm{m}^{2}\right)\end{array}$ & $\begin{array}{c}\text { Mineral } \\
(\%)\end{array}$ & $\begin{array}{c}\text { Abundance } \\
(\%)\end{array}$ & $\begin{array}{c}\log \\
(\mathrm{TP}) \\
(\mu \mathrm{g} / \mathrm{g})\end{array}$ & $\begin{array}{c}\log \\
(\mathrm{AFDM}) \\
\left(\mathrm{g} / \mathrm{m}^{2}\right)\end{array}$ \\
\hline Abundance (\%) & $0.71^{*}$ & & & & $0.88^{*}$ & & & & 0.10 & & & \\
\hline $\log (\mathrm{TP})(\mu \mathrm{g} / \mathrm{g})$ & $-0.68^{*}$ & $-0.76^{*}$ & & & $-0.80^{*}$ & $-0.82^{*}$ & & & $-0.61^{*}$ & 0.00 & & \\
\hline $\begin{array}{c}\log (\mathrm{AFDM}) \\
\left(\mathrm{g} / \mathrm{m}^{2}\right)\end{array}$ & $0.66^{*}$ & $0.85^{*}$ & $-0.85^{*}$ & & $0.87^{*}$ & $0.96^{*}$ & $-0.86^{*}$ & & $0.83^{*}$ & 0.04 & $-0.69^{*}$ & \\
\hline $\begin{array}{c}\log (\text { conductivity) } \\
(\mu \mathrm{S} / \mathrm{cm})\end{array}$ & $-0.56^{*}$ & $-0.62^{*}$ & $0.86^{*}$ & $-0.86^{*}$ & 0.57 & 0.48 & -0.05 & 0.35 & 0.51 & $-0.71^{*}$ & $-0.73^{*}$ & 0.12 \\
\hline
\end{tabular}

vironmental variables directly. Consistent with other studies, we found that high concentrations of mat TP are associated with decreased mat biomass at all 3 locations (Gaiser et al. 2006, La Hée and Gaiser 2012). However, calcareous mat biomass was negatively affected by elevated conductivity only in the Everglades. This finding probably is a consequence of elevated $\mathrm{P}$ in coastal waters of the Everglades
(Childers et al. 2006) rather than of conductivity directly, especially considering that conductivity did not have a negative effect on mat biomass in the Yucatan or Belize, where conductivity and TP were not correlated. As expected, the low abundance of mat microhabitat when $P$ was elevated had a stronger influence on the relative abundance of the regional E. evergladianum population than its presumed

Table 2. Results of the multiple linear regressions on Encyonema evergladianum \% relative abundance against total P (TP), conductivity (cond), ash-free dry mass (AFDM), and \% mineral content for the combined data set and each individual wetland. $\mathrm{SE}=$ standard error. ${ }^{*}=p<0.1,{ }^{* * *}=p<0.05$.

\begin{tabular}{|c|c|c|c|c|c|c|c|c|c|}
\hline \multirow[b]{2}{*}{ Region } & \multirow[b]{2}{*}{ Adjusted $R^{2}$} & \multirow[b]{2}{*}{$F$} & \multirow[b]{2}{*}{$p$} & \multirow[b]{2}{*}{ Predictors } & \multicolumn{2}{|c|}{ Unstandardized coefficient } & \multirow{2}{*}{$\frac{\begin{array}{c}\text { Standardized } \\
\text { coefficient }\end{array}}{\beta}$} & \multirow[b]{2}{*}{$t$} & \multirow[b]{2}{*}{$p$} \\
\hline & & & & & $\beta$ & SE & & & \\
\hline \multirow[t]{5}{*}{ Combined } & 0.582 & 11.78 & 0.000 & (Constant) & 46.715 & 35.867 & & 1.302 & 0.204 \\
\hline & & & & $\log (\mathrm{TP})$ & -9.164 & 13.332 & -0.128 & -0.687 & 0.498 \\
\hline & & & & $\log ($ Cond $)$ & -12.41 & 8.95 & -0.186 & -1.387 & 0.177 \\
\hline & & & & $\log (\mathrm{AFDM})^{*}$ & 11.361 & 5.779 & 0.406 & 1.966 & 0.060 \\
\hline & & & & Mineral & 0.352 & 0.21 & 0.335 & 1.677 & 0.105 \\
\hline \multirow[t]{5}{*}{ Everglades } & 0.725 & 8.264 & 0.009 & (Constant) & -133.501 & 91.187 & & -1.464 & 0.187 \\
\hline & & & & $\log (\mathrm{TP})$ & -17.458 & 20.177 & -0.320 & -0.865 & 0.416 \\
\hline & & & & $\log ($ Cond $)$ & 53.056 & 33.524 & 0.579 & 1.583 & 0.158 \\
\hline & & & & $\log (\text { AFDM })^{* *}$ & 29.707 & 11.255 & 0.950 & 2.639 & 0.033 \\
\hline & & & & Mineral & 0.171 & 0.199 & 0.193 & 0.855 & 0.421 \\
\hline \multirow[t]{5}{*}{ Belize } & 0.925 & 34.698 & 0.000 & (Constant) & -6.145 & 52.119 & & -0.118 & 0.909 \\
\hline & & & & $\log (\mathrm{TP})$ & -40.780 & 32.106 & -0.366 & -1.270 & 0.245 \\
\hline & & & & $\log ($ Cond $)$ & 41.806 & 22.509 & 0.345 & 1.857 & 0.106 \\
\hline & & & & $\log (\text { AFDM })^{* * *}$ & 28.938 & 8.087 & 0.730 & 3.579 & 0.009 \\
\hline & & & & Mineral & -0.345 & 0.441 & -0.240 & -0.783 & 0.459 \\
\hline \multirow[t]{5}{*}{ Yucatan } & 0.895 & 15.99 & 0.023 & (Constant) & 297.547 & 43.943 & & 6.771 & 0.007 \\
\hline & & & & $\log (\mathrm{TP})^{* * *}$ & -43.522 & 12.242 & -0.739 & -3.555 & 0.038 \\
\hline & & & & $\log (\text { Cond })^{* * *}$ & -51.504 & 8.957 & -1.369 & -5.750 & 0.010 \\
\hline & & & & $\log (\text { AFDM })^{*}$ & -20.744 & 6.915 & -0.387 & -3.000 & 0.058 \\
\hline & & & & Mineral & 0.483 & 0.229 & 0.333 & 2.115 & 0.125 \\
\hline
\end{tabular}


A
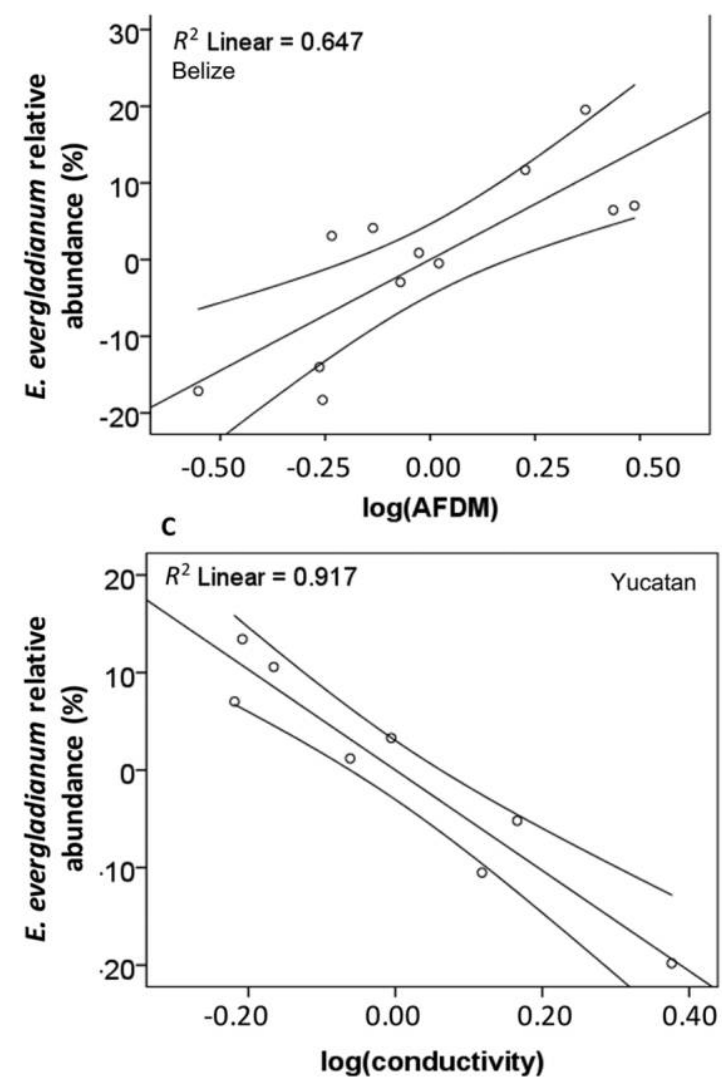

B
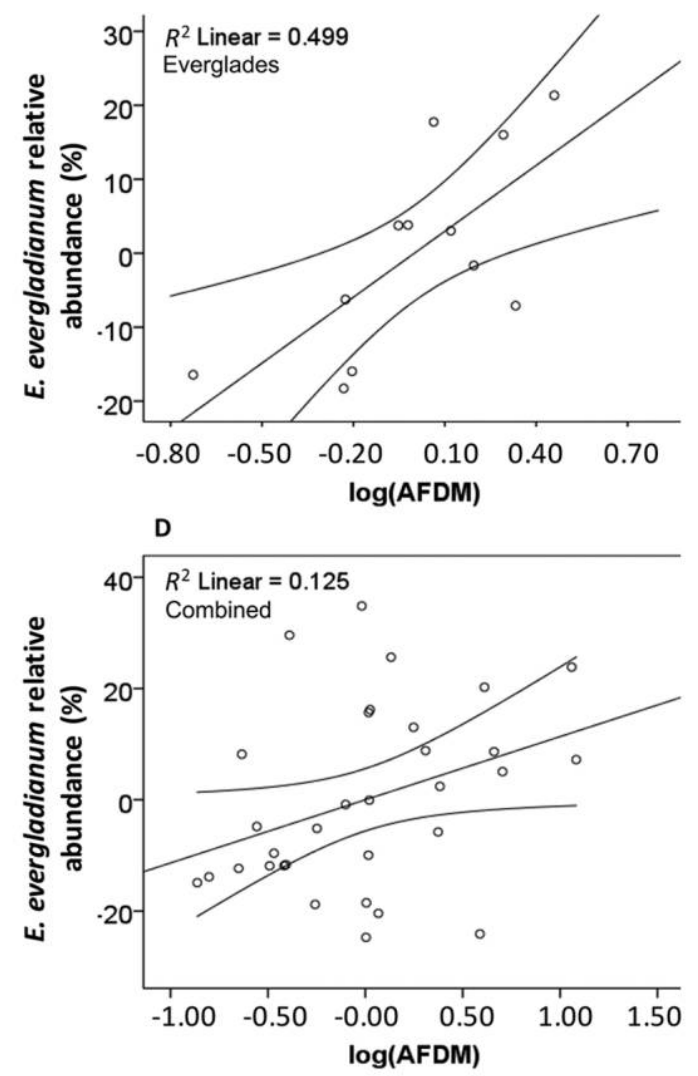

Figure 2. Partial regression plots with confidence intervals of significant predictors of Encyonema evergladianum abundance in Belize (AFDM) (A), Everglades (AFDM) (B) Yucatan (conductivity) (C), and the 3 locations combined (AFDM) (D). AFDM = ash-free dry mass.

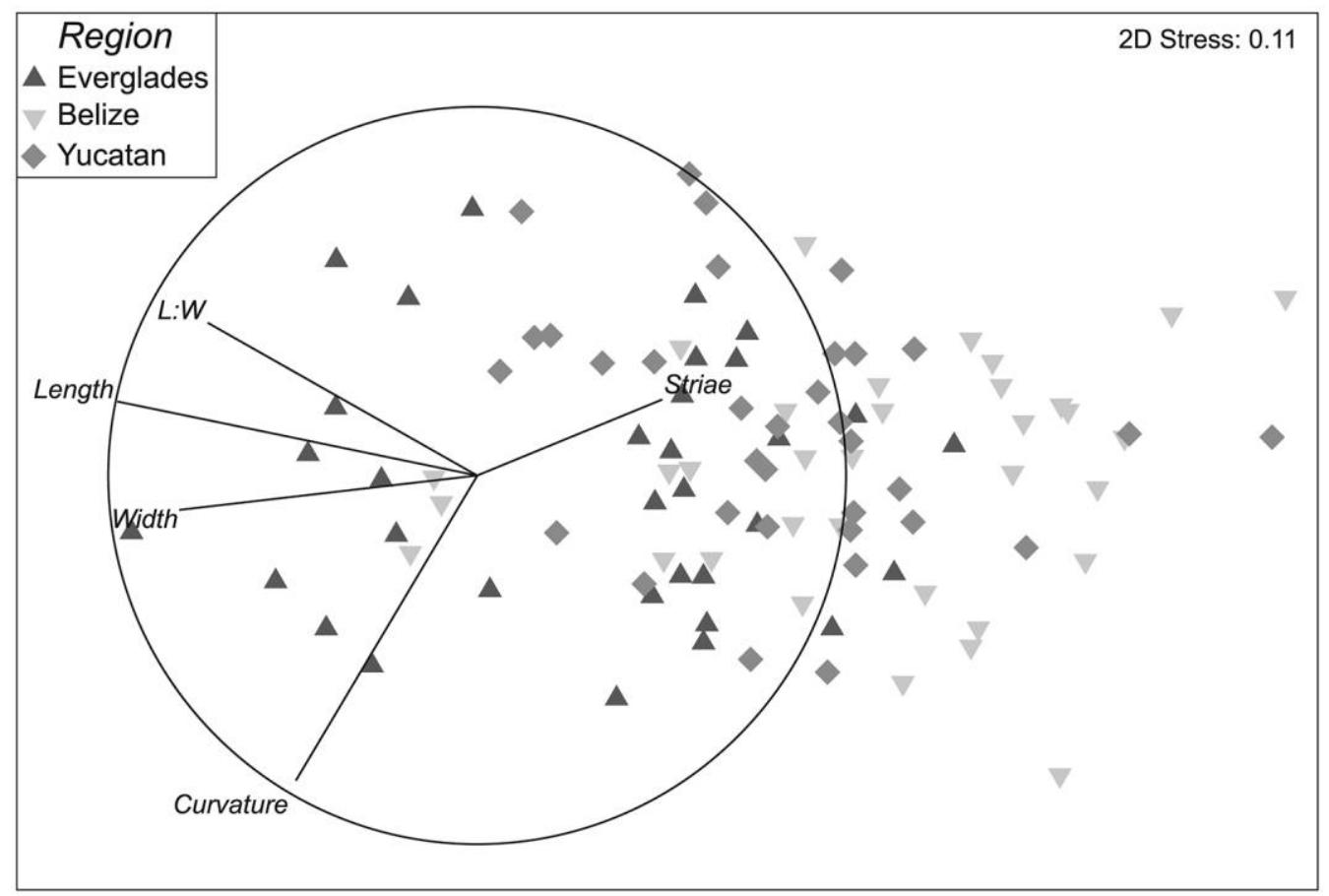

Figure 3. Nonmetric multidimensional scaling ordination of morphological data showing specimen groupings by location. $\mathrm{L}: \mathrm{W}=$ length : width ratio. 
A

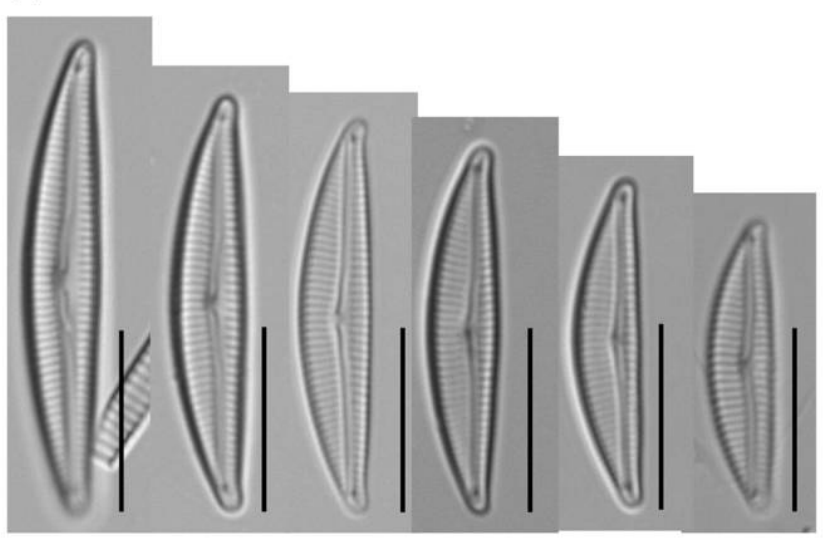

B

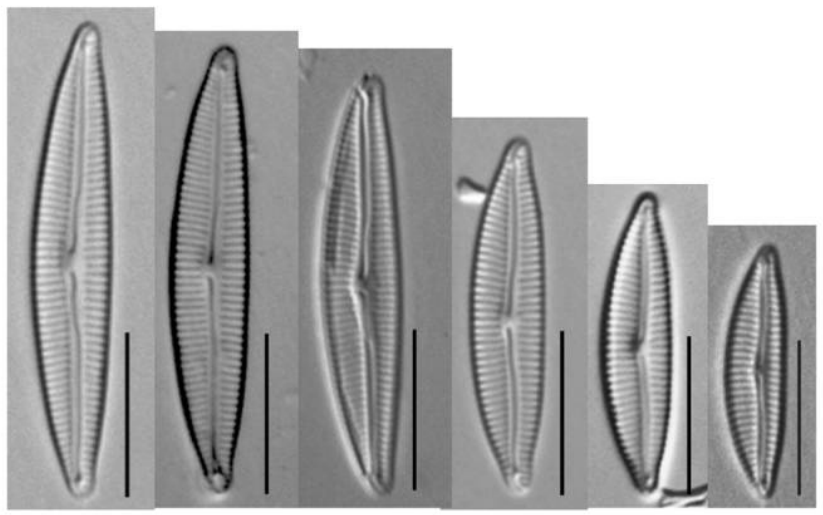

C

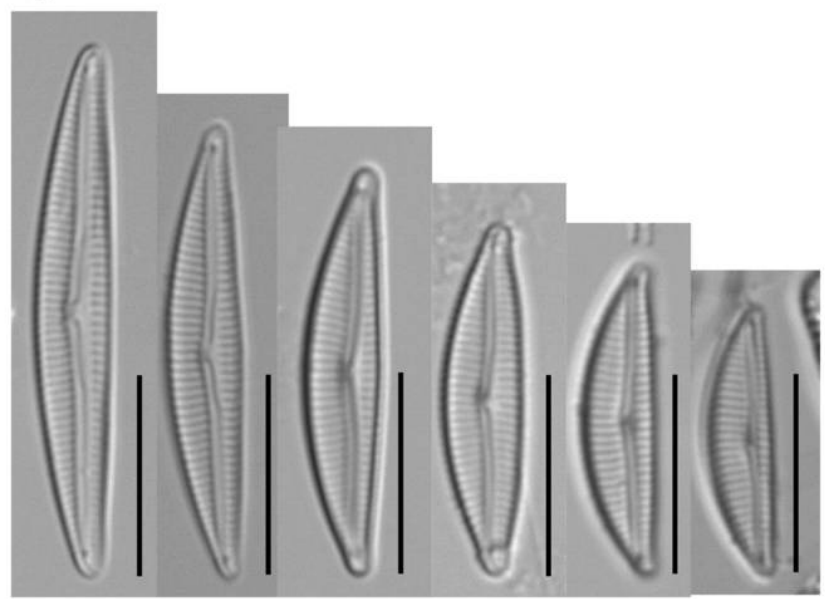

Figure 4. Size declinations of Encyonema evergladianum from Belize (A), Everglades (B), and Yucatan (C). Scale bar $=10 \mu \mathrm{m}$.

requirements for low conductivity and $\mathrm{P}$. This finding is supported by results of other studies in which microhabitat specialization was demonstrated in microorganisms. For example, Besemer et al. (2012) studied community assembly in stream biofilm microhabitats and found that biofilm community structure was not a stochastic product of random colonization by microbes from the overlying water into the biofilm. Instead, the biofilm acted as a finescale environmental filter that selected for a specific biofilm community.

Despite the apparent response of the regional E. evergladianum population to microhabitat availability, the 3 populations did not respond to the same drivers at the local scale. Unlike the Everglades and Belize populations, where microbial mat AFDM was the strongest predictor of abundance, the Yucatan population responded most strongly to conductivity and mat TP. Furthermore, inconsistent interactions between predictor variables within individual wetlands indicated that their environments differ to some degree, despite reports of environmental and floristic similarity among karstic wetlands in the Caribbean (EstradaLoera 1991, La Hée 2010, Gaiser et al. 2010). Therefore, at the local scale, specialization appears to be context dependent, such that historical or extant environmental conditions at each location may have caused ecotypic differentiation in this diatom.

Ecotypes evolve because of environmental heterogeneity or dispersal limitation (Whitaker 2006, Lee and Olds 2011). However, dispersal barriers are unlikely to exist for diatoms at the distance between karstic wetlands in the Caribbean Basin. Evidence for dispersal limitation of microorganisms has been mounting (Whitaker et al. 2003, Vanormelingen et al. 2008), but dispersal limitation is highly scale-dependent and most investigators have found that it plays an important role only at large spatial scales (van der Gucht et al. 2007, Potapova and Charles 2002). For example, Bennett et al. (2010) found that dispersal limitation is important for diatoms only at the intercontinental scale, whereas at the regional scale $\left(<1,000,000 \mathrm{~km}^{2}\right)$ a single environmental factor explained $5 \times$ more of the community variation than space. The maximum distance between wetlands in our study was $<1500 \mathrm{~km}$, supporting the idea that environmental heterogeneity, and not restricted gene flow caused by dispersal limitation, has facilitated divergent selection and ecotypic differentiation of E. evergladianum in the Caribbean Basin.

Ecological differences among ecotypes may be correlated with morphological characteristics that can be used to distinguish between ecotypes. Morphological difference is particularly important in studies where species identification is based largely on morphology, as is often the case in diatom research. We were unable to detect morphological correlates associated with the response of E. evergladianum to ecological drivers in our study. The significant morphological differences among specimens from the 3 wetlands were not consistent with the patterns of ecological differentiation detected by the regression analysis. Molecular tests could help to identify an underlying genetic component that is not morphologically expressed and that might explain the 
Table 3. Mean morphometric data for Encyonema evergladianum specimens from the Everglades, Belize, and Yucatan $(n=35 /$ site). $\mathrm{SD}=$ standard deviation, $\min =$ minimum, $\max =$ maximum .

\begin{tabular}{|c|c|c|c|c|c|c|c|c|c|c|c|c|c|c|c|c|c|c|c|c|}
\hline \multirow[b]{2}{*}{ Location } & \multicolumn{4}{|c|}{ Length $(\mu \mathrm{m})$} & \multicolumn{4}{|c|}{ Width $(\mu \mathrm{m})$} & \multicolumn{4}{|c|}{ Striae $/ 10 \mu \mathrm{m}$} & \multicolumn{4}{|c|}{$\mathrm{L}: \mathrm{W}$} & \multicolumn{4}{|c|}{ Curvature $(1 / \mu \mathrm{m})$} \\
\hline & Mean & SD & Min & Max & Mean & SD & Min & $\operatorname{Max}$ & Mean & SD & Min & Max & Mean & $\mathrm{SD}$ & Min & Max & Mean & SD & Min & Max \\
\hline Combined & 21.5 & 3.6 & 13.5 & 33.3 & 4.1 & 0.4 & 3.2 & 5.1 & 22.2 & 1.1 & 20.0 & 24.0 & 5.2 & 0.6 & 3.9 & 7.0 & 9.2 & 1.8 & 5.6 & 14.8 \\
\hline Everglades & 23.5 & 3.7 & 16.4 & 33.3 & 4.5 & 0.3 & 3.8 & 5.0 & 21.1 & 0.7 & 20.0 & 22.0 & 5.3 & 0.6 & 3.9 & 6.6 & 9.9 & 2.1 & 6.7 & 14.8 \\
\hline Belize & 19.6 & 3.2 & 14.8 & 27.2 & 3.8 & 0.4 & 3.2 & 5.1 & 22.7 & 0.9 & 21.0 & 24.0 & 5.1 & 0.6 & 4.0 & 6.4 & 8.9 & 1.6 & 5.9 & 11.7 \\
\hline Yucatan & 21.3 & 2.9 & 13.5 & 26.7 & 3.9 & 0.3 & 3.2 & 4.6 & 22.9 & 0.8 & 21.0 & 24.0 & 5.4 & 0.6 & 4.2 & 7.0 & 8.8 & 1.4 & 5.6 & 11.7 \\
\hline
\end{tabular}

ecological differences observed for the Yucatan population. Such data could indicate whether the ecological differences are a result of ecotypic differentiation rather than sampling biases or other confounding factors. Molecular studies also would allow us to test the possibility that E. evergladianum contains cryptic diversity, i.e., genetically distinct species that are morphologically indistinguishable. Several diatoms previously considered one species based on morphological characteristics alone have been found to possess ecologically differentiated cryptic species, including Navicula phyllepta
A

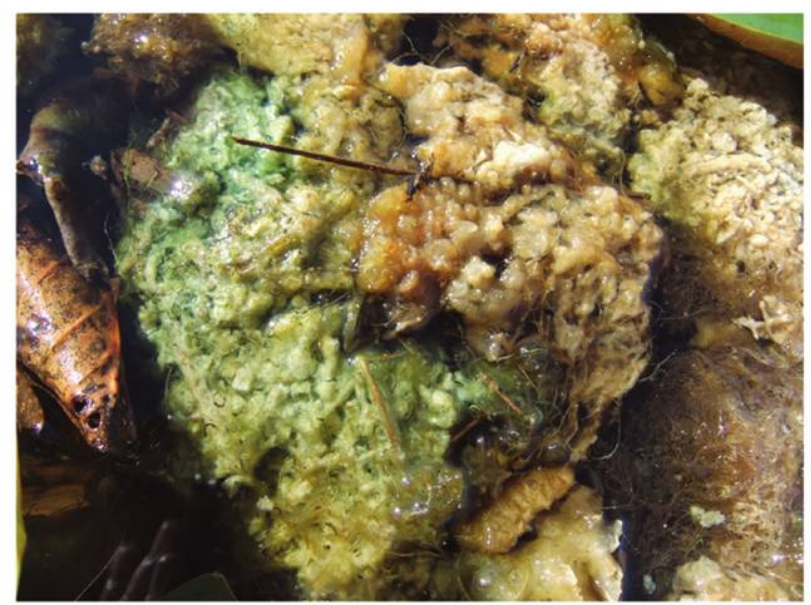

C

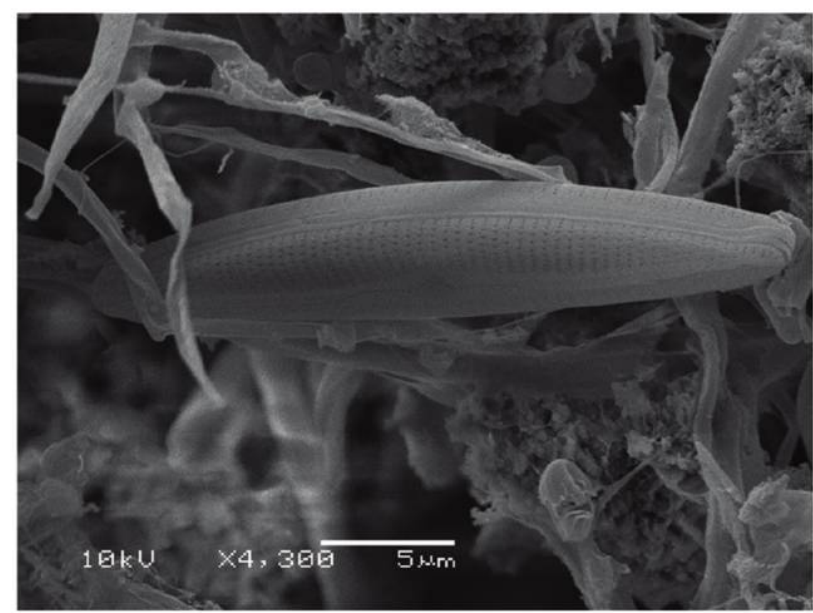

B

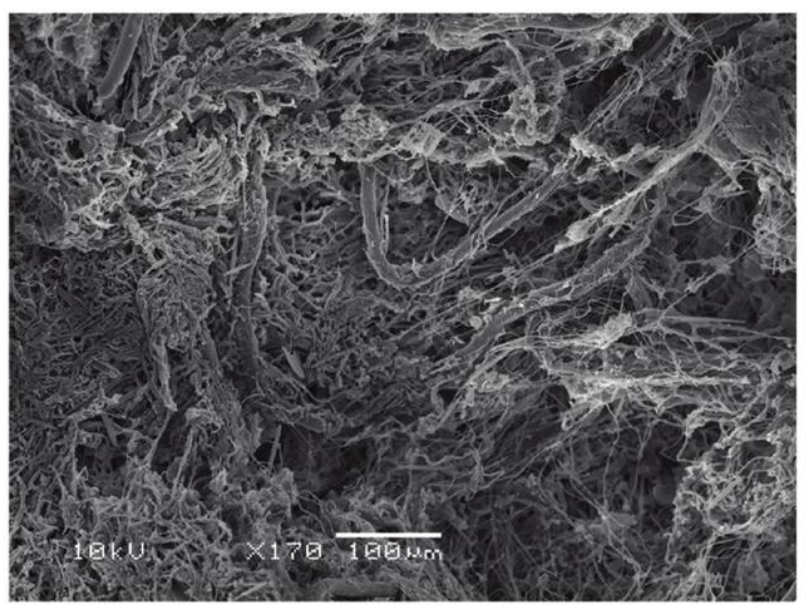

D

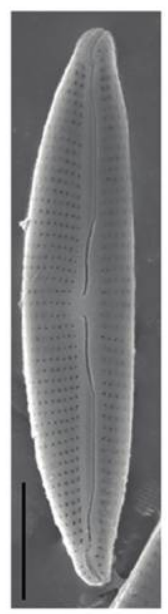

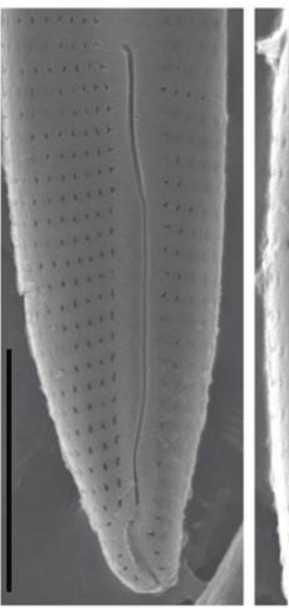

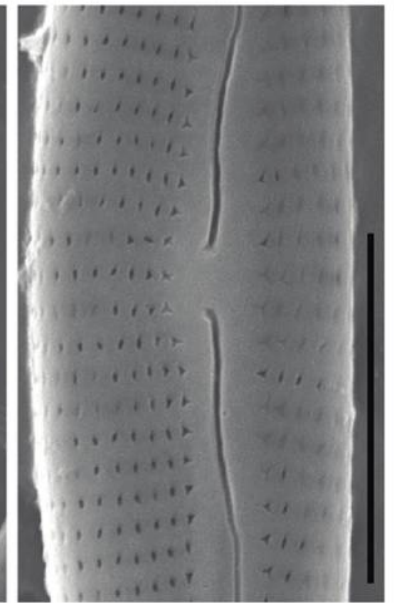

Figure 5. Photograph of typical calcareous periphyton mat (A), scanning electron micrograph of the internal mat structure (B), Encyonema evergladianum embedded within the mat matrix $(\mathrm{C})$, and scanning electron micrographs of E. evergladianum (scale bar $=$ $5 \mu \mathrm{m})(\mathrm{D})$. 
(Vanelslander et al. 2009), Sellaphora pupula (Poulíčková et al. 2008), and Skeletonema costatum (Balzano et al. 2010). Therefore, investigators of ecotypic differentiation in specialist diatom species should use a combination of ecological, morphological, and genetic tests to assess whether divergent selection for locally favored genotypes has led to the divergence of specialization across space and whether these differences are expressed morphologically.

Observation of microbial mat fragments and E. evergladianum ultrastructural features under the SEM did not reveal an engineering role in mat structure for this diatom. This result suggests a lack of functional specialization and was surprising because this diatom is found in high relative abundance in calcareous mats and could be expected to have some effect on its immediate environment. Gaiser et al. (2010) found that Mastogloia calcarea, another dominant mat-dwelling diatom from the Caribbean Basin, contributes to mat structure via production of mucilaginous strands issued from marginal pores along the valve mantle. Encyonema evergladianum does not possess any mucilage-secreting pores or mucilaginous sheaths that might contribute to mat formation and cohesion. However, its high relative abundance within calcareous mats suggests that some other microhabitat characteristic not measured here is responsible for E. evergladianum's affinity to calcareous periphyton or that it plays an important functional role in these mats that has yet to be determined. For instance, calcareous microbial mats may provide protection from grazing and desiccation or may concentrate certain ions, such as $\mathrm{Ca}^{2+}$ and $\mathrm{HCO}_{3}{ }^{-}$ favored by E. evergladianum. Calcium carbonate in the mats undergoes dissolution resulting in the production of soluble calcium bicarbonate at night when $\mathrm{pH}$ becomes elevated in the absence of photosynthesis (Merz 1992, Hagerthey et al. 2011). Ca is an important nutrient in diatom growth, particularly for the cymbelloid group to which E. evergladianum belongs, and can enhance the adhesion of diatoms to polysaccharides, an abundant component of periphyton mats (Patrick 1977, Geesey et al. 2000, Potapova and Charles 2003). Cymbelloid diatoms also have high optima for $\mathrm{HCO}_{3}{ }^{-}$ (the other ion produced through the dissolution of calcium carbonate), which is used as the inorganic $C$ source for photosynthesis and may indicate that these diatoms are able to precipitate calcium carbonate, thereby contributing to mat structure (Tortell et al. 1997, Potapova and Charles 2003).

In conclusion, our study supports the idea that specialization is not a stable ecological trait (Barnagaud et al. 2011) and that the degree of specialization is scale and context dependent. Despite local specialization differences, E. evergladianum is associated with pristine conditions found in karstic wetlands and, thus, represents a potentially powerful tool to track and predict environmental modifications caused by climate irregularities and anthropogenic pressures that threaten these unique wetlands. However, the application of this species as an indicator at the regional scale may result in overlooking or misinterpreting local change unless responses are calibrated based on conditions within individual wetlands. Genetic studies of E. evergladianum from karstic wetlands throughout the Caribbean are necessary to be certain of ecotypic differentiation within this species. In addition, the exact driver of E. evergladianum dominance within the calcareous periphyton diatom community requires further elucidation to define its niche adequately and to use it confidently as an ecological indicator in karstic wetlands.

\section{ACKNOWLEDGEMENTS}

Author contributions: VM and EG conceived the questions and hypotheses together. VM and EG conducted the field methods. VM conducted the laboratory methods, statistical analysis, and manuscript writing. EG contributed significantly to interpretation of statistical results and provided in-depth edits and comments on manuscript drafts.

We thank Franco Tobias for field and laboratory assistance; Josette La Hée for providing the Caribbean data sets; John Kominoski, Luca Marazzi, Jennifer Richards, Associate Editor Steven Francoeur, and 2 anonymous referees for reviewing and providing comments that significantly improved the quality of this manuscript; Mark Edlund and Sarah Spaulding for their help with the species treatment conducted during the Ecology and Systematics of Diatoms course at Iowa Lakeside Laboratory. This work was supported in part by the National Science Foundation through the Florida Coastal Everglades Long-Term Ecological Research program under Cooperative Agreements DEB-1237517, DBI-0620409, and DEB-9910514, and by the Everglades Foundation. This is contribution number 824 from the Southeast Environmental Research Center in the Institute of Water and Environment at Florida International University.

\section{LITERATURE CITED}

Balzano, S., D. Sarno, and W. H. C. F. Kooistra. 2010. Effects of salinity on the growth rate and morphology of ten Skeletonema strains. Journal of Plankton Research 33:937-945.

Barnagaud, J. Y., V. Devictor, F. Jiguet, and F. Archaux. 2011. When species become generalists: on-going large-scale changes in bird habitat specialization. Global Ecology and Biogeography 20:630-640.

Bennett, J. R., B. F. Cumming, B. K. Ginn, and J. P. Smol. 2010. Broad-scale environmental response and niche conservatism in lacustrine diatom communities. Global Ecology and Biogeography 19:724-732.

Besemer, K., H. Peter, J. B. Logue, S. Langenheder, E. S. Lindström, L. J. Tranvik, and T. J. Battin. 2012. Unraveling assembly of stream biofilm communities. ISME Journal 6:1459-1468.

Bixby, R. J., and E. C. Zeek. 2010. A simple method for calculating valve curvature. Proceedings of the Academv of Natural Sciences of Philadelphia 160:73-81.

Bolnick, D. I., R. Svanbäck, J. A. Fordyce, L. H. Yang, J. M. Davis, C. D. Hulsey, and M. L. Forister. 2003. The ecology of individ- 
uals: incidence and implications of individual specialization. American Naturalist 161:1-28.

Bramburger, A. J., J. W. Munyon, and E. E. Gaiser. 2013. Water quality and wet season diatom assemblage characteristics from the Tamiami Trail pilot swales sites (Everglades National Park, Florida, USA). Phytotaxa 127:163-182.

Chase, J. M., and J. A. Myers. 2011. Disentangling the importance of ecological niches from stochastic processes across scales. Philosophical Transactions of the Roval Society of London Series B: Biological Sciences 366:2351-2363.

Childers, D. L., J. N. Boyer, S. E. Davis, C. J. Madden, D. T. Rudnick, and F. H. Sklar. 2006. Relating precipitation and water management to nutrient concentrations in the oligotrophic "upside-down" estuaries of the Florida Everglades. Limnology and Oceanography 51:602-616.

Devictor, V., J. Clavel, R. Julliard, S. Lavergne, D. Mouillot, W. Thuiller, P. Venail, S. Villeger, and N. Mouquet. 2010. Defining and measuring ecological specialization. Journal of Applied Ecology 47:15-25.

Estrada-Loera, E. 1991. Phytogeographic relationships of the Yucatan Peninsula. Journal of Biogeography 18:687-697.

Frankovich, T. A., E. E. Gaiser, J. C. Zieman, and A. H. Wachnicka. 2006. Spatial and temporal distributions of epiphytic diatoms growing on Thalassia testudinum Banks ex König: relationships to water quality. Hydrobiologia 569:259-271.

Frankovich, T. A., and A. Wachnicka. 2015. Epiphytic diatoms along phosphorus and salinity gradients in Florida Bay (Florida, USA), an illustrated guide and annotated checklist. Pages 241-288 in J. A. Entry, A. D. Gottlieb, K. Jayachandran, and A. Ogram (editors). Microbiology of the Everglades ecosystem. CRC Press, Boca Raton, Florida.

Futuyma, D. J., and G. Moreno. 1988. The evolution of ecological specialization. Annual Review of Ecology and Systematics 19: 207-233.

Gaiser, E., J. M. La Hée, F. A. C. Tobias, A. H. Wachnicka. 2010. Mastogloia smithii var. lacustris Grun.: a structural engineer of calcareous periphyton mats in karstic subtropical wetlands. Proceedings of the Academy of Natural Sciences of Philadelphia 160:99-112.

Gaiser, E. E., E. P. Anderson, E. Castañeda-Moya, L. ColladoVides, J. W. Fourqurean, M. R. Heithaus, R. Jaffé, D. Lagomasino, N. J. Oehm, R. M. Price, and V. H. Rivera-Monroy. 2015. New perspectives on an iconic landscape from comparative international long-term ecological research. Ecosphere 6:1-18.

Gaiser, E. E., P. V. McCormick, S. E. Hagerthey, and A. D. Gottlieb. 2011. Landscape patterns of periphyton in the Florida Everglades. Critical Reviews in Environmental Science and Technology 41:92-120.

Gaiser, E. E., L. J. Scinto, J. H. Richards, K. Jayachandran, D. L. Childers, J. C. Trexler, and R. D. Jones. 2004. Phosphorus in periphyton mats provides the best metric for detecting lowlevel P enrichment in an oligotrophic wetland. Water Research 38:507-516.

Gaiser, E. E., J. C. Trexler, R. D. Jones, D. L. Childers, J. H. Richards, and L. J. Scinto. 2006. Periphyton responses to eutrophication in the Florida Everglades: cross-system patterns of structural and compositional change. Limnology and Oceanography 51:617-630.
Geesey, G. G., B. Wigglesworth-Cooksey, and K. E. Cooksey. 2000. Influence of calcium and other cations on surface adhesion of bacteria and diatoms: a review. Biofouling 15:195-205.

Hagerthey, S. E., B. J. Bellinger, K. Wheeler, M. Gantar, E. Gaiser. 2011. Everglades periphyton: a biogeochemical perspective. Critical Reviews in Environmental Science and Technology 41:309-342.

Hasle, G. R., and G. A. Fryxell. 1970. Diatoms: cleaning and mounting for light and electron microscopy. Transactions of the American Microscopical Society 89:469-474.

Kolasa, J., and T. N. Romanuk. 2005. Assembly of unequals in the unequal world of a rock pool metacommunity. Pages 212-232 in M. Holyoak, M. A. Leibold, and R. D. Holt (editors). Metacommunities: spatial dynamics and ecological communities. University of Chicago Press, Chicago, Illinois.

Krammer, K. 1997. Die cymbelloiden Diatomeen. Eine Monographie der weltweit bekannten Taxa. Teil 2. Encyonema part., Encyonopsis and Cymbellopsis. Bibliotheca Diatomologica 37: $1-469$.

La Hée, J. M. 2010. The influence of phosphorus on periphyton mats from the Everglades and three tropical karstic wetlands. Florida Institute of Technology Electronic Theses and Dissertations. Paper 251. Florida Institute of Technology, Miami, Florida.

La Hée, J. M., and E. E. Gaiser. 2012. Benthic diatom assemblages as indicators of water quality in the Everglades and three tropical karstic wetlands. Freshwater Science 31:205-221.

Lee, S. S., E. E. Gaiser, and J. C. Trexler. 2013. Diatom-based models for inferring hydrology and periphyton abundance in a subtropical karstic wetland: implications for ecosystemscale bioassessment. Wetlands 33:157-173.

Lee, C. R., and T. M. Olds. 2011. Quantifying effects of environmental and geographical factors on patterns of genetic differentiation. Molecular Ecology 20:4631-4642.

Mazzei, V. 2014. Encyonema evergladianum. In Diatoms of the United States. US Geological Survey/Institute of Arctic and Alpine Research, University of Colorado, Boulder, Colorado. (Available from: http://westerndiatoms.colorado.edu/taxa /species/encyonema_evergladianum)

Merz, M. U. 1992. The biology of carbonate precipitation by cyanobacteria. Facies 26:81-101.

Pandit, S. N., J. Kolasa, and K. Cottenie. 2009. Contrasts between habitat generalists and specialists: an empirical extension to the basic metacommunity framework. Ecology 90:2253-2262.

Patrick, R. 1977. Ecology of freshwater diatoms and diatom communities. Biology of Diatoms 13:284-332.

Poisot, T., J. D. Bever, A. Nemri, P. H. Thrall, and M. E. Hochberg. 2011. A conceptual framework for the evolution of ecological specialisation. Ecology Letters 14:841-851.

Potapova, M., and D. F. Charles. 2002. Benthic diatoms in USA rivers: distributions along spatial and environmental gradients. Journal of Biogeography 29:167-187.

Potapova, M., and D. F. Charles. 2003. Distribution of benthic diatoms in US rivers in relation to conductivity and ionic composition. Freshwater Biology 48:1311-1328.

Poulí̌ková, A., J. Špačková, M. G. Kelly, M. Duchoslav, and D. G. Mann. 2008. Ecological variation within Sellaphora species complexes (Bacillariophyceae): specialists or generalists? $\underline{\mathrm{Hy}-}$ drobiologia 614:373-386. 
Price, R. M., P. K. Swart, and J. W. Fourqurean. 2006. Coastal groundwater discharge-an additional source of phosphorus for the oligotrophic wetlands of the Everglades. Hydrobiologia 569:23-36.

Rejmánková, E., and J. Komárková. 2005. Response of cyanobacterial mats to nutrient and salinity changes. Aquatic Botany 83:87-107.

Saha, A. K., S. Saha, J. Sadle, J. Jiang, M. S. Ross, R. M. Price, L. S. Sternberg, and K. S. Wendelberger. 2011. Sea level rise and South Florida coastal forests. Climatic Change 107:81-108.

Slate, J. E., and R. J. Stevenson. 2007. The diatom flora of phosphorus enriched and unenriched sites in an Everglades marsh. Diatom Research 22:355-386.

Soininen, J. 2007. Environmental and spatial control of freshwater diatoms-a review. Diatom Research 22:473-490.

Solórzano, L., and J. H. Sharp. 1980. Determination of total dissolved phosphorus and particulate phosphorus in natural waters. Limnology and Oceanography 25. doi:10.4319/lo.1980. 25.4.0754

Sultan, S. E., and H. G. Spencer. 2002. Metapopulation structure favors plasticity over local adaptation. American Naturalist 160: 271-283.

Tortell, P. D., J. R. Reinfelder, and F. M. Morel. 1997. Active uptake of bicarbonate by diatoms. Nature 390:243-244.

van der Gucht, K., K. Cottenie, K. Muylaert, N. Vloemans, S. Cousin, S. Declerck, E. Jeppesen, J. M. Conde-Porcuna, K. Schwenk, G. Zwart, and H. Degans. 2007. The power of species sorting: local factors drive bacterial community composition over a wide range of spatial scales. Proceedings of the
National Academv of Sciences of the United States of America 104:20404-20409.

Vanelslander, B., V. Creach, P. Vanormelingen, A. Ernst, V. A. Chepurnov, E. Sahan, G. Muyzer, L. J. Stal, W. Vyverman, and K. Sabbe. 2009. Ecological differentiation between sympatric pseudocryptic species in the estuarine benthic diatom Navicula phyllepta (Bacillariophyceae). $\underline{\text { Journal of Phycology }}$ 45:1278-1289.

Vanormelingen, P., E. Verleyen, and W. Vyverman. 2008. The diversity and distribution of diatoms: from cosmopolitanism to narrow endemism. Biodiversity and Conservation 17:393-405.

van Tienderen, P. H. 1991. Evolution of generalists and specialist in spatially heterogeneous environments. Evolution 45:1317-1331.

Wachnicka, A., E. Gaiser, L. Collins, T. Frankovich, and J. Boyer. 2010. Distribution of diatoms and development of diatombased models for inferring salinity and nutrient concentrations in Florida Bay and adjacent coastal wetlands of south Florida (USA). Estuaries and Coasts 33:1080-1098.

Weiher, E., D. Freund, T. Bunton, A. Stefanski, T. Lee, and S. Bentivenga. 2011. Advances, challenges and a developing synthesis of ecological community assembly theory. Philosophical Transactions of the Roval Society of London Series B: Biological Sciences 366:2403-2413.

Whitaker, R. J. 2006. Allopatric origins of microbial species. Philosophical Transactions of the Roval Societv of London Series B: Biological Sciences 361:1975-1984.

Whitaker, R. J., D. W. Grogan, and J. W. Taylor. 2003. Geographic barriers isolate endemic populations of hyperthermophilic archaea. Science 301:976-978. 